\title{
Evidence for a Catabolic Role of Glucagon during an Amino Acid Load
}

\author{
Michael R. Charlton, Deborah B. Adey, and K. Sreekumaran Nair
}

Endocrine Research Unit, Mayo Clinic and Foundation, Rochester, Minnesota 55905; and University of Vermont, Burlington,

Vermont 05405

\section{Abstract}

Despite the strong association between protein catabolic conditions and hyperglucagonemia, and enhanced glucagon secretion by amino acids (AA), glucagon's effects on protein metabolism remain less clear than on glucose metabolism. To clearly define glucagon's catabolic effect on protein metabolism during AA load, we studied the effects of glucagon on circulating AA and protein dynamics in six healthy subjects. Five protocols were performed in each subject using somatostatin to inhibit the secretion of insulin, glucagon, and growth hormone (GH) and selectively replacing these hormones in different protocols. Total AA concentration was the highest when glucagon, insulin, and GH were low. Selective increase of glucagon levels prevented this increment in AA. Addition of high levels of insulin and GH to high glucagon had no effect on total AA levels, although branched chain AA levels declined. Glucagon mostly decreased glucogenic AA and enhanced glucose production. Endogenous leucine flux, reflecting proteolysis, decreased while leucine oxidation increased in protocols where AA were infused and these changes were unaffected by the hormones. Nonoxidative leucine flux reflecting protein synthesis was stimulated by AA, but high glucagon attenuated this effect. Addition of GH and insulin partially reversed the inhibitory effect of glucagon on protein synthesis. We conclude that glucagon is the pivotal hormone in amino acid disposal during an AA load and, by reducing the availability of AA, glucagon inhibits protein synthesis stimulated by AA. These data provide further support for a catabolic role of glucagon at physiological concentrations. (J. Clin. Invest. 1996. 98:90-99.) Key words: glucagon - protein synthesis • amino acids $\bullet$ leucine kinetics $\bullet$ glucose

Address correspondence to K. Sreekumaran Nair, M.D., Ph.D., Mayo Clinic, 200 First Street SW, Endocrine Research Unit, Rochester, MN 55905. Phone: 507-255-6515; FAX: 507-255-4828; E-mail: nair.sree@mayo.edu

Received for publication 13 February 1996 and accepted in revised form 12 April 1996.

1. Abbreviations used in this paper: AA, amino acids; BCAA, branched-chain amino acids; I, insulin; KIC, ketoisocaproic acid; SRIH, somatostatin.

The Journal of Clinical Investigation

Volume 98, Number 1, July 1996, 90-99

\section{Introduction}

Glucagon has a well-defined role in glucose homeostasis. In contrast, glucagon's effects on amino acid (AA) ${ }^{1}$ and protein metabolism are poorly defined. However, there is considerable indirect evidence to suggest a catabolic role for glucagon in protein metabolism in humans. Hyperglucagonemia occurs in a variety of catabolic conditions. These include trauma, burns, sepsis, cirrhosis, glucagonoma, the postoperative state, and poorly controlled type I diabetes (1-5). In patients with glucagonoma, in which glucose metabolism is only minimally disturbed, there is marked muscle wasting, skin atrophy, and hypoaminocidemia (6). In these patients there is a reduction of free intracellular branched-chain amino acids (BCAA) in liver and muscle (7). It has been postulated that accelerated oxidation of BCAA is a cause of their decreased intracellular concentrations. We have demonstrated previously that high glucagon levels, during insulin deficiency, are associated with an increase in leucine oxidation in healthy human volunteers (8). Given that leucine is not directly involved in gluconeogenesis, this accelerated oxidation of leucine in the setting of hyperglucagonemia is an especially important finding. In addition, a decline in the elevation of glucogenic amino acids that is seen in pancreatectomized patients occurs with glucagon replacement (9). A catabolic role for glucagon, mainly to incoming protein, has been proposed (10).

In normal physiology, protein meals, with their attendant amino acid loads, stimulate glucagon, growth hormone, and insulin secretion. It is believed that the purpose of the aminogenic glucagon release is, by stimulating hepatic glucose production, to avert hypoglycemia resulting from the concomitant insulin secretion $(11,12)$. It has been proposed that glucagon is involved in the disposal of amino acids after a protein meal. Furthermore, glucagon has been reported to increase the disposal of amino acids during mixed amino acids infusions (13). Direct evidence for and the mechanism of this reported effect have not yet been elucidated.

The current studies were designed to test the hypotheses that glucagon plays a critical role in the disposal of amino acids during an amino acid load and to determine the mechanism of this AA disposal by performing simultaneous measurement of amino acid concentrations, whole body protein turnover, and glucose kinetics.

\section{Methods}

\section{Subjects}

We studied six healthy adult volunteers (three male and three female). Age was $22.4 \mathrm{yr}$ (19-25 range), weight $67.8 \mathrm{~kg}(\mathrm{SEM} \pm 5.92 \mathrm{~kg})$, and height $165.1(\mathrm{SEM} \pm 4.52 \mathrm{~cm})$. All volunteers were within $10 \%$ of ideal body weight for height and were screened by detailed history, physical examination, and biochemical profile (urine and blood) for any overt illness. Subjects on any regular medications were excluded. Studies involving women volunteers were always carried out during the luteal phase of the menstrual cycle. 


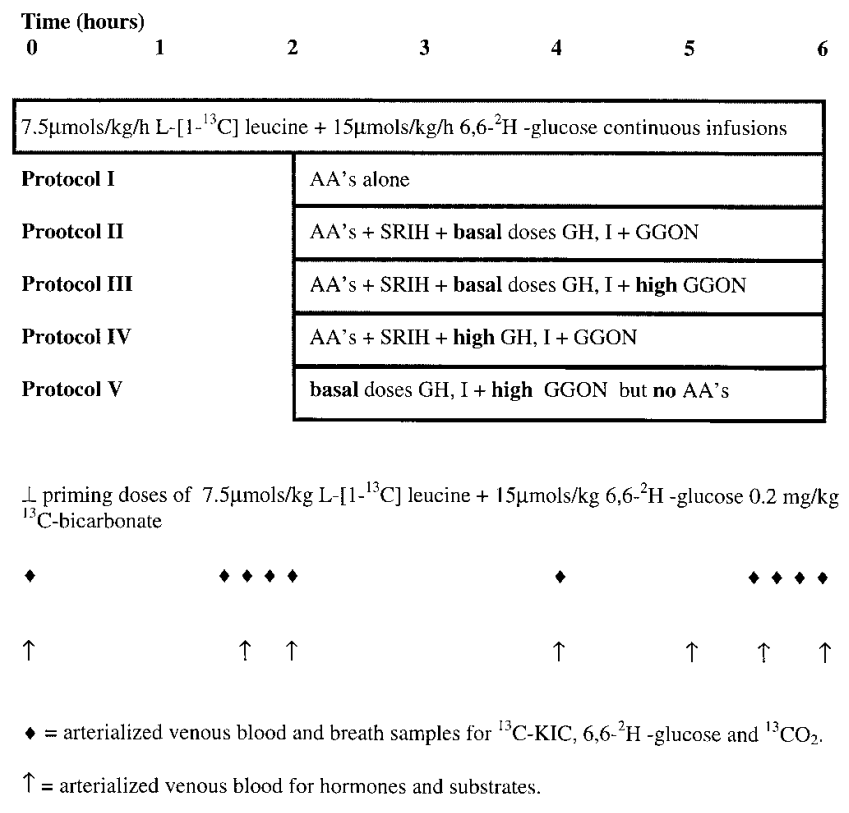

Figure 1. AA's, mixed amino acid infusion at a rate of $1.5 \mathrm{ml} / \mathrm{kg} / \mathrm{h}$ (Aminosyn 15\%); SRIH, $500 \mu \mathrm{g} / \mathrm{h} ; G H$, human growth hormone (replacement dose $=0.5 \mu \mathrm{g} / \mathrm{kg} / \mathrm{h}$, high dose $=1.0 \mu \mathrm{g} / \mathrm{kg} / \mathrm{h}) ; I$, regular insulin (replacement dose $=0.10 \mathrm{mU} / \mathrm{kg} / \mathrm{min}$, high dose $=0.4 \mathrm{mU} / \mathrm{kg} /$ $\mathrm{min}$ ); GGON, glucagon (replacement dose $=1.0 \mathrm{ng} / \mathrm{kg} / \mathrm{min}$, high dose $=6.0 \mathrm{ng} / \mathrm{kg} / \mathrm{min}$ ). Indirect calorimetry was obtained between 300 and $330 \mathrm{~min}$. Normal saline was infused at a rate of $1.5 \mathrm{ml} / \mathrm{kg} / \mathrm{h}$ for the first $2 \mathrm{~h}$ of all five protocols.

Informed written consent was obtained after detailed explanation of the protocol, which had been approved by the Human Investigation Committee of the University of Vermont.

\section{Materials}

We obtained L- $\left[1-{ }^{13} \mathrm{C}\right]$ leucine, $\left[6,6-{ }^{2} \mathrm{H}_{2}\right]$ glucose, and ${ }^{13} \mathrm{C}$-sodium bicarbonate from Cambridge Isotopes (Cambridge, MA). Chemical, isotopic, and optical purity of the isotopes were confirmed before use. Solutions of the isotopes were prepared under sterile precautions and were tested for pyrogens and sterility before use.

\section{Study design}

All subjects were placed on a weight maintaining diet (percent carbohydrate/protein/fat $=55: 15: 30$ ) for $3 \mathrm{~d}$ before each of the protocols. Weights were measured before each study to document weight stability. Subjects were admitted to the Clinical Research Center of the University of Vermont $1 \mathrm{~d}$ before each study. Each volunteer was studied on five separate occasions. Studies were separated by at least $3 \mathrm{wk}$. The sequence in which the five studies were carried out was assigned in a random fashion. All volunteers completed each of the five study protocols, i.e., 30 experiments were conducted in total. Volunteers were admitted to the General Clinical Research Center the afternoon before each of the five studies. After an evening meal, served no later than 6:00 p.m., the subjects were fasted until after the completion of the study. Water intake was freely permitted. The protocols for each of the five studies are described below.

\section{Common protocol for all five studies}

At 7:00 a.m. of each study day, an 18-gauge venous catheter was placed in a retrograde fashion in a dorsal hand vein. The hand with this catheter was then rested in a "hot box" that circulated air at a temperature of $60^{\circ} \mathrm{C}$ to arterialize the venous blood (14). Arterialized venous blood has been shown to truly reflect ${ }^{13} \mathrm{C}$-labeled leucine and ketoisocaproic acid (KIC) values obtained from arterial blood (15). A second 18-gauge catheter was placed in the contralateral forearm for infusions. Once baseline blood and expired air samples were obtained, bolus doses of ${ }^{13} \mathrm{C}$-sodium bicarbonate $(1.5 \mu \mathrm{mol} / \mathrm{kg})$ and $\mathrm{L}-\left[1-{ }^{13} \mathrm{C}\right] \mathrm{leu}-$ cine $(7.5 \mu \mathrm{mol} / \mathrm{kg})$ were given to prime the respective pools to achieve early isotopic plateaus $(16,17)$. After isotope boluses had been administered and continuous infusion of $\mathrm{L}-\left[1-{ }^{13} \mathrm{C}\right]$ leucine at a rate of $7.5 \mu \mathrm{mol} / \mathrm{kg} / \mathrm{h}$ had begun, an infusion of normal saline at a rate of $1.5 \mathrm{ml} / \mathrm{kg} / \mathrm{h}$ was initiated for the first $2 \mathrm{~h}$ of each study. After $2 \mathrm{~h}$ of each study, one of the following five infusion protocols was begun and continued for $4 \mathrm{~h}$ until completion of the study. A schema for the five protocols is shown in Fig. 1.

Protocol I: Mixed amino acids infusion (AA). Infusion of mixed amino acids (Aminosyn 15\%; Abbott Laboratories, Chicago, IL) was started at a rate of $1.5 \mathrm{ml} / \mathrm{kg} / \mathrm{h}$. This proprietary mixture of amino acids contained the following amino acids in the concentrations shown $(\mathrm{mg} / 100 \mathrm{ml})$ : isoleucine 990 , leucine 1,500, lysine 1,575, methionine 258 , phenylalanine 447 , threonine 600 , tryptophan 300 , valine 750 , alanine 1,490, arginine 1,527, histidine 450, proline 1,083, serine 795, tyrosine 405 , glycine 750 , glutamic acid 1,107 , aspartic acid 1,050. No cysteine, glutamine, asparagine, or taurine was present in the preparation. In addition, sodium $62.7 \mathrm{meq} / \mathrm{liter}$ and acetate $107.6 \mathrm{meq} / \mathrm{liter}$ were present.

Protocol II: AA + somatostatin (SRIH) + basal replacement levels of growth hormone, insulin (I), and glucagon. This comprised mixed amino acids at a rate of $1.5 \mathrm{ml} / \mathrm{kg} / \mathrm{h}$, as above. In addition, concomitant infusions of SRIH (Stilamin; Serono Laboratories, Randolph, MA) at a rate of $500 \mu \mathrm{g} / \mathrm{h}$, recombinant human growth hormone (Genentech, South San Francisco, CA) at a rate of $0.5 \mu \mathrm{g} / \mathrm{kg} / \mathrm{h}$, insulin at a rate of $0.10 \mathrm{mU} / \mathrm{kg} / \mathrm{min}$, and glucagon at a rate of $1.0 \mathrm{ng} / \mathrm{kg} / \mathrm{min}$.

Protocol III: AA + SRIH + basal replacement levels of growth hormone and $I+$ high levels of glucagon. This comprised mixed amino acids at a rate of $1.5 \mathrm{ml} / \mathrm{kg} / \mathrm{h}$, as above. In addition, concomitant infusions of SRIH at a rate of $500 \mu \mathrm{g} / \mathrm{h}$, growth hormone at a rate of 0.5 $\mu \mathrm{g} / \mathrm{kg} / \mathrm{h}$, insulin at a rate of $0.10 \mathrm{mU} / \mathrm{kg} / \mathrm{min}$, and glucagon at a higher rate of infusion at $6.0 \mathrm{ng} / \mathrm{kg} / \mathrm{min}$. This rate of glucagon infusion was intended to achieve similar levels of glucagon to those seen in the portal circulation after a protein meal.

Protocol IV: AA + SRIH + high levels of growth hormone, I, and glucagon. This comprised mixed amino acids at a rate of $1.5 \mathrm{ml} / \mathrm{kg} / \mathrm{h}$, as above. In addition, concomitant infusions of SRIH at a rate of 500 $\mu \mathrm{g} / \mathrm{h}$, growth hormone at a rate of $1.0 \mu \mathrm{g} / \mathrm{kg} / \mathrm{h}$, insulin at a rate of 0.40 $\mathrm{mU} / \mathrm{kg} / \mathrm{min}$, and glucagon at a rate of $6.0 \mathrm{ng} / \mathrm{kg} / \mathrm{min}$. This protocol was intended to achieve similar levels of glucagon, growth hormone, and insulin to those seen in the portal circulation after a protein meal.

Protocol V: SRIH + basal replacement of growth hormone, I + high glucagon (no $A A$ ). This comprised SRIH at a rate of $500 \mu \mathrm{g} / \mathrm{h}$, growth hormone at a rate of $0.5 \mu \mathrm{g} / \mathrm{kg} / \mathrm{h}$, insulin at a rate of $0.10 \mathrm{mU} /$ $\mathrm{kg} / \mathrm{min}$, and glucagon at the higher rate of infusion of $6.0 \mathrm{ng} / \mathrm{kg} / \mathrm{min}$ (same as protocol III).

Arterialized venous blood samples for isotope analysis were drawn at 0, 90, 100, 110, 120, 240, 330, 340, 350, and $360 \mathrm{~min}$. Expired air for isotope analysis was collected at the same intervals as blood isotope samples.

Whole body indirect calorimetry was carried out for a period of $40 \mathrm{~min}$ starting at 30 and at $320 \mathrm{~min}$ to measure $\mathrm{CO}_{2}$ production. The indirect calorimetry results from the final $30 \mathrm{~min}$ of these periods were used for calculations, allowing the first $10 \mathrm{~min}$ to obtain a steady state.

\section{Analysis of samples}

Isotopes: Plasma isotope enrichments: KIC preparation derivatization technique. To $100 \mu \mathrm{l}$ of plasma, $50 \mu \mathrm{l}$ of $10 \mu \mathrm{g} / \mathrm{ml}$ ketovaleric acid (as internal standard) was added. An equal volume of $50 \%$ acetic acid was then added to bring the $\mathrm{pH}$ to $<2$. The sample was then passed over a column containing $0.5 \mathrm{ml}$ bed volume of AG50Wx8 cation exchange resin (100-200 mesh) and the keto acids eluted with $2 \mathrm{ml}$ of deionized water. 

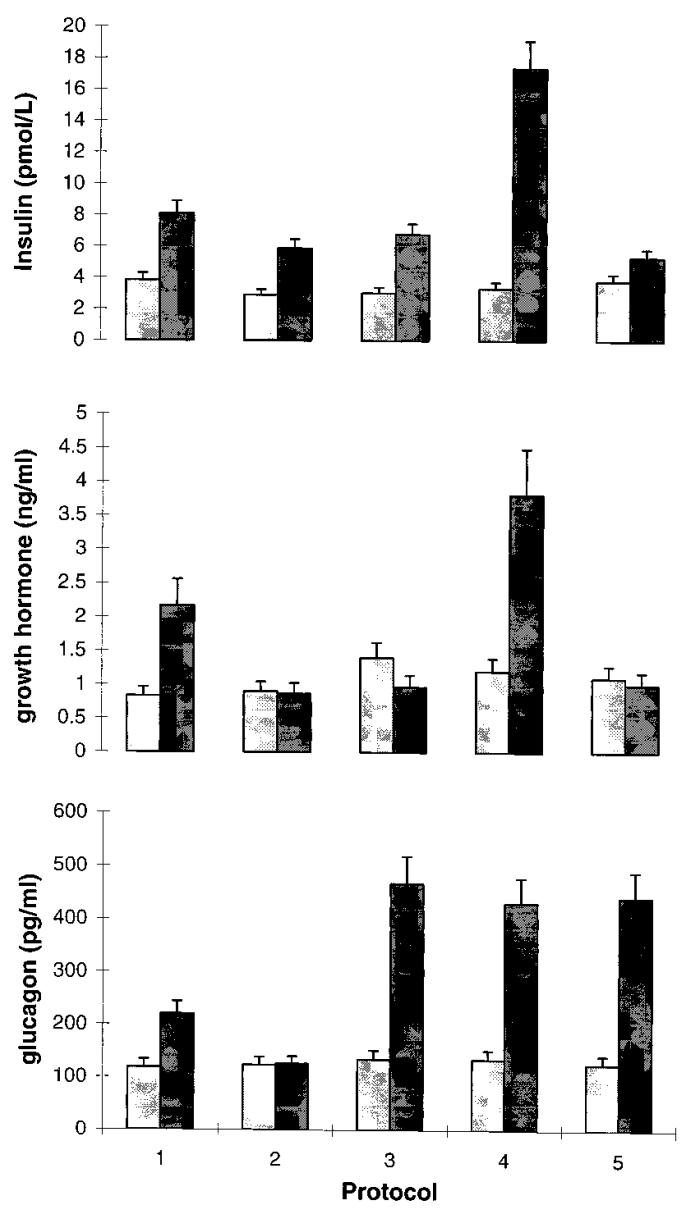

Figure 2. All hormone concentrations are expressed as mean values for the baseline (0-120 min; light gray bars) and plateau (300-360 min; dark gray bars) periods. The mean plateau value of insulin was significantly higher $(P<0.001)$ during protocol IV (when high levels of insulin were infused systemically) than in any of the other protocols. Mean plateau glucagon levels were higher in protocols III, IV, and $\mathrm{V}$ (when high levels of glucagon were infused systemically) than in protocols I (amino acids alone) $(P<0.001)$ and II (when amino acids were infused with replacement glucagon $)(P<0.0001)$. Growth hormone levels were significantly higher in protocols I and IV than in protocols II, III, or V.

The eluted ketoacid was derivatized with a quinoxalinol bis-trimethylsilyl tri-fluoroacetic (BSTFA) anhydride and pyridine. The ${ }^{13} \mathrm{C}$-KIC enrichment was then determined by selected ion monitoring and electron impact ionization in a quadropole gas chromatograph mass spectrometer, monitoring ions m/z 259 and 260 (15-18).

KIC concentration was measured using ketovaleric acid as an internal standard.

${ }^{13} \mathrm{CO}_{2}$ enrichments in expired air. Expired air samples were collected in a modified Foley catheter bag and transferred into a $20 \mathrm{ml}$ Vacutainer. The isotopic enrichment of ${ }^{13} \mathrm{CO}_{2}$ in expired air was measured with an isotope ratio mass spectrometer as described previously $(17,18)$.

\section{Calculations}

Leucine was chosen as a tracer because it is an essential amino acid in humans. In the steady state, leucine flux calculated from carboxyllabeled leucine is equivalent to proteolysis as proteolysis is the only source of nonlabeled leucine in fasting humans (i.e., rate of appearance of unlabeled leucine equals the rate of proteolysis). In the steady state, rates of appearance and disappearance of leucine are equal and are represented by leucine flux. The leucine disappearance rate is equal to the sum of leucine incorporated into protein and leucine oxidation. Leucine oxidation can be directly measured and, by subtracting leucine oxidation from leucine flux (same as rate of disappearance), a putative measure of protein synthesis (nonoxidative disposal of leucine) can be made.

Leucine kinetics were calculated using the isotopic enrichments of ${ }^{13} \mathrm{C}$-KIC obtained between 90 and $120 \mathrm{~min}$ for baseline and between 330 and 360 min for the plateau periods, by which times steady states had been achieved (Fig. 2). Leucine oxidation was calculated from plateau values of ${ }^{13} \mathrm{CO}_{2}$ production rate and using plasma ${ }^{13} \mathrm{C}$-KIC enrichment as the precursor pool $(18,19)$.

${ }^{13} \mathrm{CO}_{2}$ production rate $\left(\mathrm{F}^{13} \mathrm{CO}_{2}\right)$ was calculated from ${ }^{13} \mathrm{CO}_{2}$ enrichment and $\mathrm{CO}_{2}$ production rate as described previously and leucine oxidation was calculated using plasma ${ }^{13} \mathrm{C}-\mathrm{KIC}$ at plateau as the precursor (16-21).

Leucine flux $\left(Q_{L}\right)$ was calculated as follows: $Q_{L}=i($ Ei/Ep-1) $\mathrm{mmol} / \mathrm{kg} / \mathrm{h}$; where $i$ is the infusion rate $(\mathrm{mmol} / \mathrm{kg} / \mathrm{h})$. During amino acid infusions, such as occurred in four of the five protocols, to obtain endogenous leucine flux (proteolysis or protein breakdown) the rate of appearance of leucine secondary to the exogenous amino acid infusion is subtracted from the total leucine flux.

Protein synthesis was indirectly estimated by calculating the nonoxidative portion of leucine flux, i.e.: Nonoxidative leucine disposal $=$ leucine flux - leucine oxidation.

\section{Glucose}

In the fasted state the whole body rate of appearance of $\left(R_{\mathrm{a}}\right)$ of glucose is equivalent to the sum of glycogenolysis and gluconeogenesis. The rates of appearance of glucose or endogenous glucose production were calculated by applying the same dilution principle as for leucine flux (22).

\section{Hormones and substrates}

Plasma glucose concentrations were measured enzymatically with an auto analyzer (Beckman Instruments, Fullerton, CA). Amino acid concentrations were measured by high performance liquid chromatography with fluorometric detection with precolumn O-phthalaldehyde derivatization (23). Glucagon was assayed by competitive radioimmunoassay technique using an antibody from Linco Research Laboratory (St. Louis, MO). Growth hormones were measured by radioimmunoassay using a commercial kit (Diagnostic Systems Laboratories, Inc., Webster, TX). Insulin was measured by chemiluminescent sandwich assay (Sanofi Diagnostics, Chaska, MN). Glycerol was measured using the free glycerol assay kit and $\beta$-hydroxybutyrate was measured using the $\beta$-hydroxybutyrate assay kit (Sigma Chemical Corp., St. Louis, MO).

\section{Data analysis}

All results are expressed as mean \pm SEM. Differences between baseline and plateau values were compared using a paired $t$ test.

Data analysis was carried out with the SAS software package (SAS Inc., Cary, NC). ANOVA was used to compare treatments and covariance with hormone levels and infusion of amino acids. After a significant treatment effect, individual variance was used to compare individual treatment means.

\section{Results}

\section{Hormones}

Glucagon. Glucagon levels at baseline and during the plateau period are shown in Fig. 2. Mean plateau glucagon levels were similar in protocols III, IV, and V when high levels of glucagon were infused peripherally. The mean plateau glucagon level in protocol I (AAs only) was less than half of the levels seen in protocols III, IV, and V, in which high levels of glucagon were infused. Assuming 30-40\% first-pass hepatic extraction of 

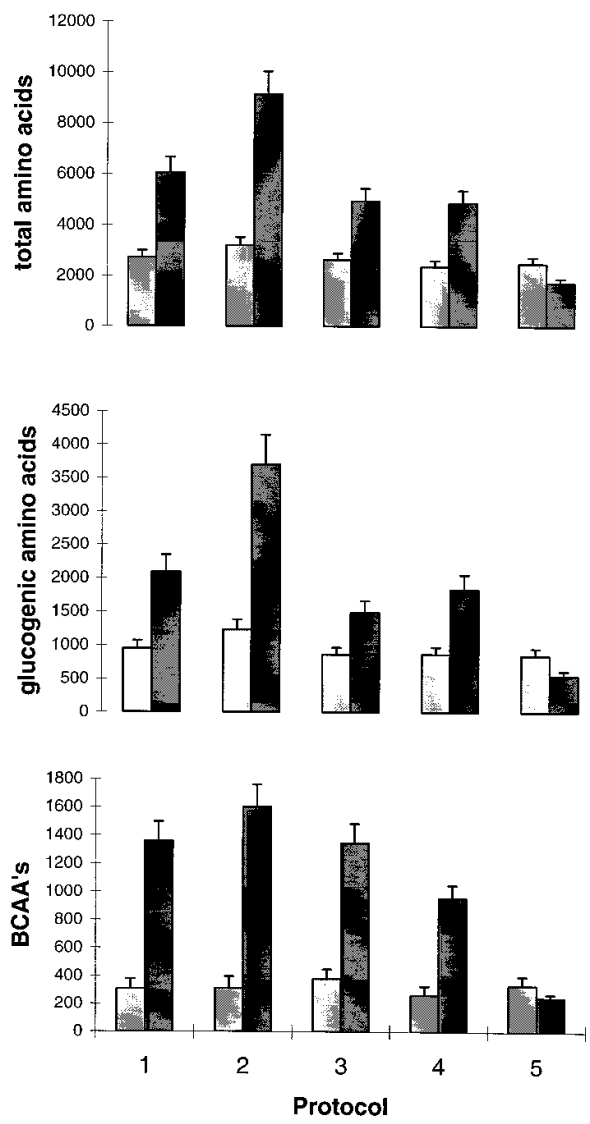

Figure 3. All amino acid concentrations are expressed as mean values for the baseline (0-120 min; light gray bars) and plateau (300-360 min; dark gray bars) periods. Total amino acid concentrations increased at plateau from baseline in all protocols (I-IV) in which AA mixture was infused $(P<0.001)$. In protocol $\mathrm{V}$ there was a decline in the total amino acids at plateau $(P<0.05)$. In all protocols except protocol V, glucogenic AA and BCAA increased at plateau $(P<$ $0.01)$. The increase of glucogenic amino acids was the highest in protocol II which was higher than in all other protocols $(P<0.01)$. The increment of BCAA at plateau was lower in protocol IV than in protocols I-III. Mean plateau glucogenic amino acid concentrations were more than two times higher when glucagon levels were low (in protocol II) than when glucagon levels were high (protocols III and IV) $(P<0.003)$.

glucagon $(24,25)$, the intraportal levels of glucagon in protocol I would have been higher than the intraportal glucagon levels in protocols III, IV, and V.

The mean plateau glucagon level in protocol II, when low replacement levels of glucagon were infused, was significantly lower than the mean plateau glucagon levels seen in protocols III, IV, and V (during which high levels of glucagon were infused) $(P<0.0001)$ as well as protocol I $(P<0.05)$.

The systemic glucagon levels at plateau during protocols III and IV were $465 \pm 47 \mathrm{pg} / \mathrm{ml}$ and $430 \pm 42 \mathrm{pg} / \mathrm{ml}$, respectively, compared with $220 \pm 17 \mathrm{pg} / \mathrm{ml}$ for protocol I.

Insulin. Mean plateau insulin concentrations rose above baseline protocols I, II, III $(P<0.05)$, and IV $(P<0.0001)$ but not in protocol $\mathrm{V}(P<0.07)$. The mean plateau concentrations of insulin are shown in Fig. 2. The mean plateau values of insulin were similar in protocols I, II, III, and V. The mean plateau value of insulin was significantly higher during protocol IV than any of the other protocols $(P<0.001)$. The infusion rate
Table I. Substrate Concentrations during Plateau Period

\begin{tabular}{lcccccc}
\hline \multicolumn{1}{c}{ Protocols } & I & II & III & IV & V \\
\hline$\beta$-Hydroxybutyrate (mmol/liter) & $<0.4$ & $<0.4$ & $<0.4$ & $<0.4$ & $<0.4$ \\
Glycerol (mmol/liter) & $27 \pm 10$ & $20 \pm 8$ & $32 \pm 11$ & $18 \pm 10$ & $29 \pm 12$ \\
Free fatty acids (mmol/liter) & $43 \pm 13$ & $42 \pm 18$ & $44 \pm 14$ & $36 \pm 10$ & $60 \pm 19$
\end{tabular}

Mean plateau values \pm SEM are shown. There are no differences among the five protocols.

of insulin during protocol IV was four times higher than the rate infused in protocols II, III, or V. No insulin was infused during protocol I.

Growth hormone. Baseline and plateau growth hormone levels are shown in Fig. 3. The mean plateau growth hormone levels were significantly higher during protocols I (amino acids only) and IV (high levels of infusion of growth hormone) than during protocols II, III, or V (during which basal replacement levels of growth hormone were infused) $(P<0.006)$. Mean plateau growth hormone levels increased above baseline only in protocols I and IV $(P<0.004)$. Baseline growth hormone levels were similar in each of the five protocols.

Cortisol and catecholamines. These hormone levels did not change between baseline and plateau in any of the protocols. The mean plateau cortisol levels ranged between 5 and $28 \mathrm{mg} /$ $\mathrm{dl}$ and were also not significantly different between the five protocols. The mean plateau catecholamine levels in the five protocols varied between 21 and $45 \mathrm{pg} / \mathrm{ml}$ for epinephrine and 96 and $415 \mathrm{pg} / \mathrm{ml}$ for norepinephrine and were not significantly different between the five protocols.

\section{Substrates}

$\beta$-Hydroxybutyrate/glycerol/free fatty acids (Table I). Mean plateau values of $\beta$-hydroxybutyrate $(<0.4 \mu \mathrm{mol} /$ liter in all protocols), glycerol (range 10-35 $\mu \mathrm{mol} /$ liter), and free fatty acids (range 15-92 $\mu \mathrm{mol} /$ liter) were not significantly different between the five protocols.

Amino acids. Amino acid concentrations at baseline (90$120 \mathrm{~min}$ ) and during the plateau period (the final $60 \mathrm{~min}$ ) of each of the five protocols are shown in Table II and Fig. 3. Baseline amino acid concentrations were similar in all five of the protocols, i.e., in the fasting state.

There were clear differences in circulating amino acid concentrations between studies during the plateau period. In all protocols in which amino acids were infused (protocols I-IV) the mean concentrations at plateau of total $(P<0.0001)$, glucogenic, branched-chain, and aromatic amino acids $(P \leq$ 0.02 ) increased significantly above baseline levels.

In protocol II (AAs + infusion of basal levels of growth hormone, insulin, glucagon), the mean total amino acids concentration at plateau was $50 \%$ higher than during protocol I (amino acid infusion without manipulation of hormones) $(P<$ $0.01)$. The increase in total amino acids at plateau in protocol II was largely due to increases in the concentrations of the gluconeogenic amino acids (alanine, serine, threonine, histidine, arginine, glycine, and phenylalanine) (Table I). Conversely, when glucagon was replaced at higher levels either selectively (protocol III) or in combination with higher levels of insulin and growth hormone (protocol IV), total amino acid concentrations at plateau were significantly lower than were seen during protocol II $(P<0.001)$. The lower total amino acid levels 


\begin{tabular}{|c|c|c|c|c|c|c|c|c|c|c|}
\hline & \multicolumn{10}{|c|}{ Protocol } \\
\hline & \multicolumn{2}{|c|}{ I } & \multicolumn{2}{|c|}{ II } & \multicolumn{2}{|c|}{ III } & \multicolumn{2}{|c|}{ IV } & \multicolumn{2}{|c|}{ V } \\
\hline & Baseline & Plateau & Baseline & Plateau & Baseline & Plateau & Baseline & Plateau & Baseline & Plateau \\
\hline \multicolumn{11}{|l|}{ Amino acid } \\
\hline GLU & $203 \pm 20$ & $344 \pm 40$ & $256 \pm 30$ & $320 \pm 35$ & $182 \pm 20$ & $281 \pm 30$ & $185 \pm 20$ & $267 \pm 30$ & $170 \pm 20$ & $157 \pm 20$ \\
\hline SER & $108 \pm 10$ & $303 \pm 35$ & $124 \pm 15$ & $492 * \pm 55$ & $131 \pm 15$ & $254 \pm 30$ & $107 \pm 10$ & $261 \pm 30$ & $111 \pm 10$ & $72 \pm 10$ \\
\hline GLN & $646 \pm 70$ & $743 \pm 80$ & $772 \pm 85$ & $1164 * \pm 130$ & $631 \pm 70$ & $642 \pm 70$ & $579 \pm 65$ & $646 \pm 70$ & $589 \pm 65$ & $391 \pm 45$ \\
\hline HIS & $138 \pm 15$ & $237 \pm 25$ & $140 \pm 15$ & $310 * \pm 34$ & $138 \pm 15$ & $197 \pm 20$ & $117 \pm 15$ & $187 \pm 20$ & $126 \pm 15$ & $90 \pm 10$ \\
\hline GLY & $284 \pm 30$ & $525 \pm 60$ & $384 \pm 40$ & $944 * \pm 105$ & $239 \pm 25$ & $390 \pm 45$ & $254 \pm 30$ & $450 \pm 50$ & $244 \pm 25$ & $172 \pm 30$ \\
\hline THR & $225 \pm 25$ & $500 \pm 55$ & $194 \pm 20$ & $626 \pm 70$ & $245 \pm 25$ & $354 \pm 40$ & $235 \pm 25$ & $409 \pm 45$ & $255 \pm 30$ & $172 \pm 20$ \\
\hline ALA & $334 \pm 40$ & $764 \pm 85$ & $528 \pm 60$ & $1638^{\ddagger} \pm 180$ & $248 \pm 25$ & $485 \pm 50$ & $272 \pm 30$ & $707 \pm 80$ & $241 \pm 30$ & $135 \pm 15$ \\
\hline ARG & $214 \pm 25$ & $453 \pm 50$ & $209 \pm 20$ & $765^{*} \pm 85$ & $187 \pm 20$ & $370 \pm 40$ & $150 \pm 20$ & $376 \pm 40$ & $164 \pm 20$ & $129 \pm 15$ \\
\hline TYR & $46 \pm 5$ & $32 \pm 5$ & $44 \pm 10$ & $49^{*} \pm 5$ & $41 \pm 5$ & $28 \pm 5$ & $42 \pm 5$ & $21 \pm 2$ & $45 \pm 5$ & $27 \pm 5$ \\
\hline VAL & $149 \pm 15$ & $516 \pm 55$ & $143 \pm 15$ & $572 \pm 65$ & $223 \pm 25$ & $533 \pm 60$ & $138 \pm 15$ & $385 \pm 40$ & $174 \pm 20$ & $135 \pm 15$ \\
\hline PHE & $46 \pm 5$ & $125 \pm 15$ & $50 \pm 5$ & $178^{*} \pm 20$ & $44 \pm 5$ & $101 \pm 10$ & $39 \pm 5$ & $92 \pm 10$ & $43 \pm 5$ & $34 \pm 5$ \\
\hline ILE & $48 \pm 5$ & $299 \pm 35$ & $59 \pm 5$ & $362 \pm 40$ & $43 \pm 5$ & $285 \pm 30$ & $38 \pm 5$ & $199 \pm 20$ & $47 \pm 5$ & $29 \pm 5$ \\
\hline LEU & $110 \pm 10$ & $545 \pm 60$ & $109 \pm 10$ & $666 \pm 75$ & $113 \pm 10$ & $528 \pm 60$ & $86 \pm 10$ & $369 \pm 40$ & $110 \pm 10$ & $80 \pm 10$ \\
\hline LYS & $169 \pm 20$ & $662 \pm 70$ & $162 \pm 20$ & $1039 * \pm 115$ & $157 \pm 15$ & $499 \pm 55$ & $130 \pm 15$ & $519 \pm 55$ & $170 \pm 20$ & $109 \pm 10$ \\
\hline BCAAs & 307 & 1360 & 311 & 1600 & 379 & 1346 & 262 & 953 & 331 & 244 \\
\hline Aromatic AAs & 92 & 157 & 94 & 227 & 85 & 129 & 81 & 113 & 88 & 61 \\
\hline Glucogenic & 951 & 2092 & 1230 & 3700 & 863 & 1483 & 868 & 1827 & 851 & 551 \\
\hline Total AAs & 2720 & 6048 & 3174 & 9125 & 2622 & 4947 & 2372 & 4888 & 2489 & 1732 \\
\hline
\end{tabular}

All amino acid concentrations are expressed in $\mu \mathrm{mol} /$ liter $( \pm$ SEM) for mean values for the baseline $(0-120 \mathrm{~min})$ and plateau (300-360 min) periods. BCAA is the sum of leucine, isoleucine, and valine. The aromatic amino acids values represent the sum of phenylalanine and tyrosine. Glucogenic amino acid values represent the sum of alanine, glycine, serine, and threonine. ${ }^{*} P<0.05$ vs. protocol $\mathrm{I},{ }^{*} P<0.001$ vs. protocol I.

seen during amino acid infusions in the protocols in which glucagon levels were high (protocols III and IV) were due in large part to decline in the gluconeogenic amino acids. In protocol IV the mean total amino acid concentration at plateau was similar to the level seen in protocol III, although there was a selective decline in BCAA $(P<0.05)$ with less pronounced fall in glucogenic amino acids (Table I). Furthermore, in protocol II, the only protocol during which glucagon levels were low, the magnitude of increase above baseline for the glucogenic amino acids was twofold greater than the increase above baseline seen in any of the other protocols during which amino acids were infused $(P \leq 0.001)$. Tyrosine and glutamine concentrations increased above baseline concentrations only in protocol II whereas tyrosine levels fell significantly below baseline levels in all of the other protocols $(P \leq 0.04)$.

In protocol V (no AAs + infusion of basal growth hormone and insulin + high glucagon) the mean total amino acid concentrations at plateau fell during the infusion of high levels of glucagon when compared with baseline levels in this protocol $(P<0.02)$. Mean plateau total amino acid concentrations were significantly lower in protocol $\mathrm{V}$ than plateau values for any of the other four protocols (all of which involved the infusion of amino acids) $(P \leq 0.001)$. The magnitude of fall in amino acid concentrations at plateau during protocol $\mathrm{V}$ was greatest for the gluconeogenic amino acids.

Isotopic plateau. Isotopic plateau for ${ }^{13} \mathrm{C}-\mathrm{KIC}$ and ${ }^{13} \mathrm{CO}_{2}$ production is demonstrated in Fig. 4. The slopes of the mean values during 90-120 min and 300-360 min were not different from zero. Leucine flux and leucine oxidation were calculated using ${ }^{13} \mathrm{C}$-KIC and ${ }^{13} \mathrm{CO}_{2}$ values at baseline (90-120 min) and at plateau (300-360 $\mathrm{min})$, respectively.

Leucine kinetics (Figs. 5 and 6). Leucine flux: Baseline values $(\mu \mathrm{mol} / \mathrm{kg} / \mathrm{h})$ for leucine flux in protocols I, II, III, IV, and $\mathrm{V}$ were $92.8 \pm 1.4,96.8 \pm 2.8,97.3 \pm 2.9,94.7 \pm 2.4$, and 92.7 \pm 3.4 , respectively (Fig. 5). None of these values were significantly different from each other. The mean coefficient of variation for the baseline values for leucine flux between the five protocols was $3.4 \%$ (Fig. 6).

The changes from baseline of the mean plateau values $(\mu \mathrm{mol} / \mathrm{kg} / \mathrm{h}$ ) for the endogenous leucine flux (an index of protein breakdown) during protocols I, II, III, IV, and V were $-47 \pm 9.1,-43 \pm 8.5,-62 \pm 17.6,-33 \pm 6.5$, and $-0.5 \pm 2.2$, respectively. Percent changes from baseline for endogenous leucine flux values at plateau are shown in Fig. 5. The change from baseline was significant in protocols I-IV $(P<0.01$ to $P<0.0001)$. However, these values were not significantly different from each other. There was no change from baseline of the mean plateau value for the endogenous leucine flux in protocol V. The mean plateau value for endogenous leucine flux was significantly higher in protocol $\mathrm{V}$ than in any of the other protocols $(P \leq 0.01)$.

Leucine oxidation: The baseline values $(\mu \mathrm{mol} / \mathrm{kg} / \mathrm{h})$ for leucine oxidation in protocols I, II, III, IV, and V were $27 \pm 2.2$, $26 \pm 1.8,28 \pm 1.1,27 \pm 1.8$, and $26 \pm 1.5$, respectively. These values were not significantly different from each other. The mean coefficient of variation for the baseline values for leucine oxidation between the five protocols was $2.9 \%$ (Fig. 5).

The changes from baseline of the mean plateau values $(\mu \mathrm{mol} / \mathrm{kg} / \mathrm{h}$ ) for leucine oxidation for protocols I, II, III, IV, 


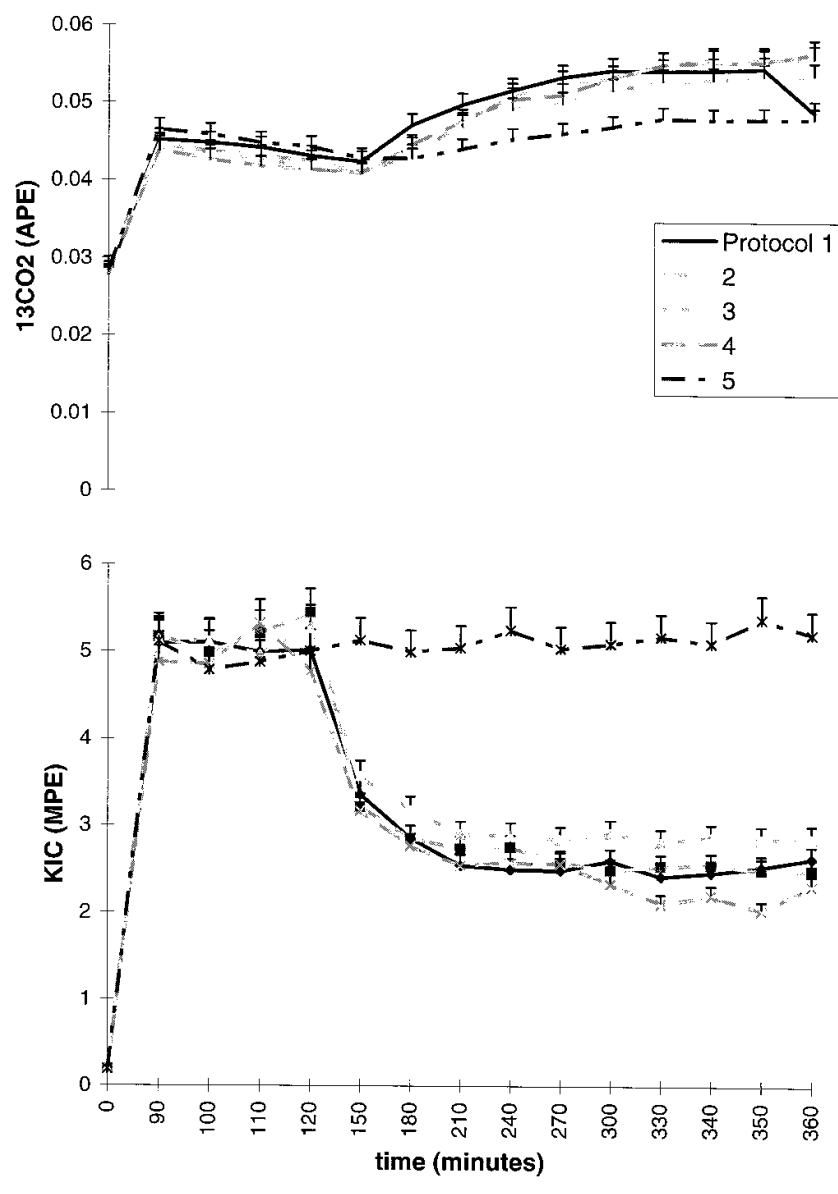

Figure 4. Time course data for ${ }^{13} \mathrm{C}$-leucine $\mathrm{KIC}$, expressed in moles percent excess $(M P E)$ and ${ }^{13} \mathrm{CO}_{2}$, expressed in atoms percent excess (APE). 0-120 min was the baseline period of each protocol. Hormone infusions were commenced at $120 \mathrm{~min}$ and continued for the remainder of each study. Leucine kinetics were calculated using the isotopic enrichments obtained between 90-120 min for baseline and between 330-360 min for the plateau periods. Error bars indicate SEM.

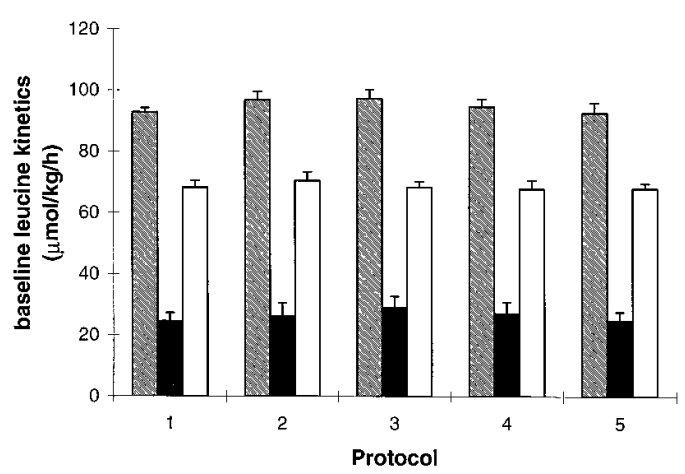

Figure 5. Mean baseline values for leucine oxidation (black bars), flux (protein breakdown) (gray bars), and nonoxidative flux (protein synthesis) (white bars). All values are expressed as $\mu \mathrm{mol} / \mathrm{kg} / \mathrm{h}$. Error bars represent SEM. The low SEMs and close grouping of these values, obtained under identical conditions, demonstrate the tight physiological control of these parameters in the postabsorptive state and the high reproducibility of these measurements using the continuous infusion stable isotope technique.
Protocol
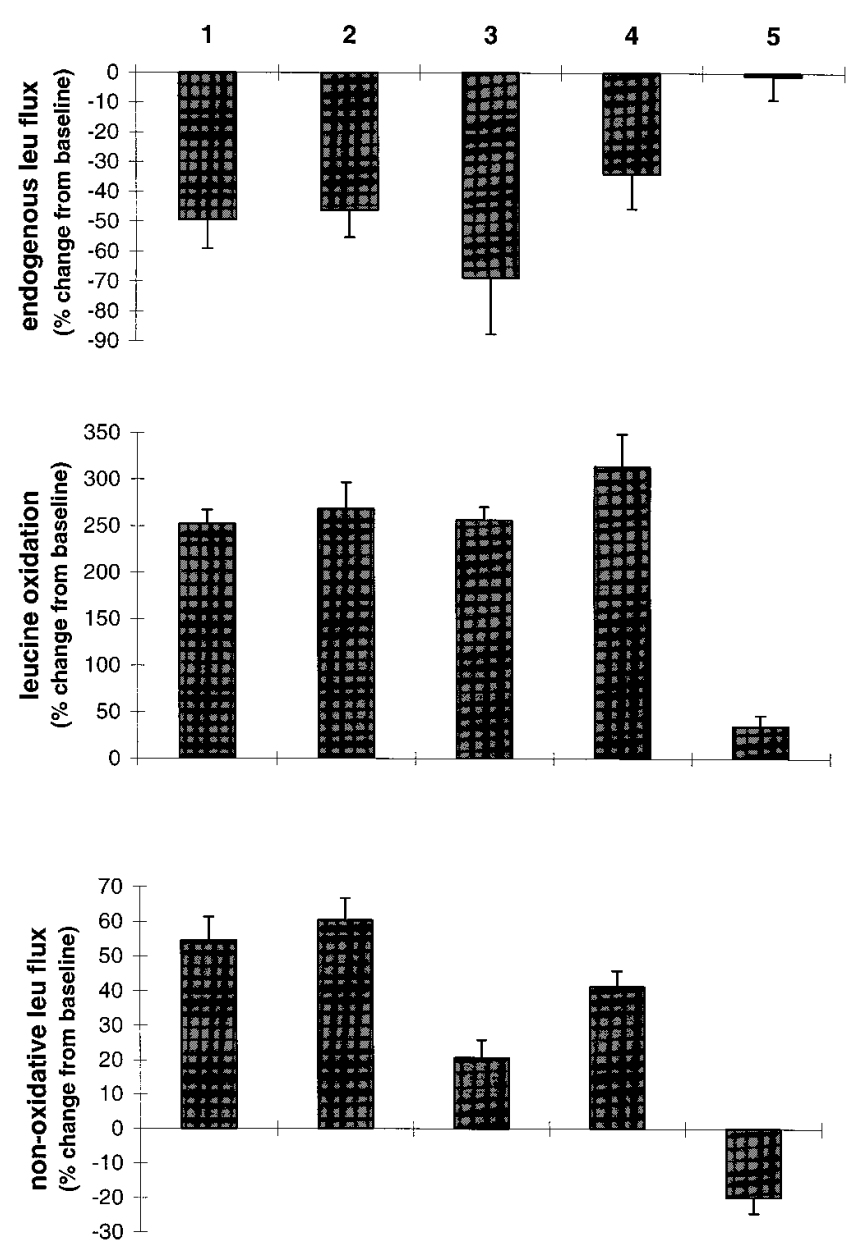

Figure 6. Columns represent percent change from baseline for leucine oxidation, endogenous leucine flux, and nonoxidative leucine flux. All values were calculated from mean values for the baseline (0-120 min) and plateau (300-360 min) periods. Endogenous leucine flux was inhibited whenever amino acids were infused (protocols I-IV) and was not different among the four (I-IV) protocols. Endogenous leucine flux was significantly higher in protocol $\mathrm{V}$ than in all other protocols $(P<0.01)$. Leucine oxidation increased significantly above baseline values in protocols I-IV $(P<0.001)$ and protocol V $(P<0.03)$. Nonoxidative leucine flux was significantly increased above baseline in all protocols during which amino acids were infused (I-IV). The percent increase was less in protocol III (during selective hyperglucagonemia) than during the protocols in which glucagon was replaced at basal levels $(P<0.04)$.

and $V$ were $68 \pm 4.1,67 \pm 7.1,64 \pm 3.5,91 \pm 10$, and $9 \pm 3$, respectively. All of these increases above their respective baseline values were significant $(P<0.001$ for protocols I-IV and $P<$ 0.03 for protocol V). Percent changes from baseline for leucine oxidation values at plateau are shown in Fig. 6.

Nonoxidative leucine flux (protein synthesis): The baseline values $(\mu \mathrm{mol} / \mathrm{kg} / \mathrm{h})$ for nonoxidative leucine flux in protocols I, II, III, IV, and V were $71 \pm 4.4,72 \pm 3.0,68 \pm 1.1,67 \pm 1.5$, and $72 \pm 4.0$, respectively. These values were not significantly different from each other. The mean coefficient of variation for the baseline values for leucine flux between the five protocols was $3.8 \%$ (Fig. 5). 

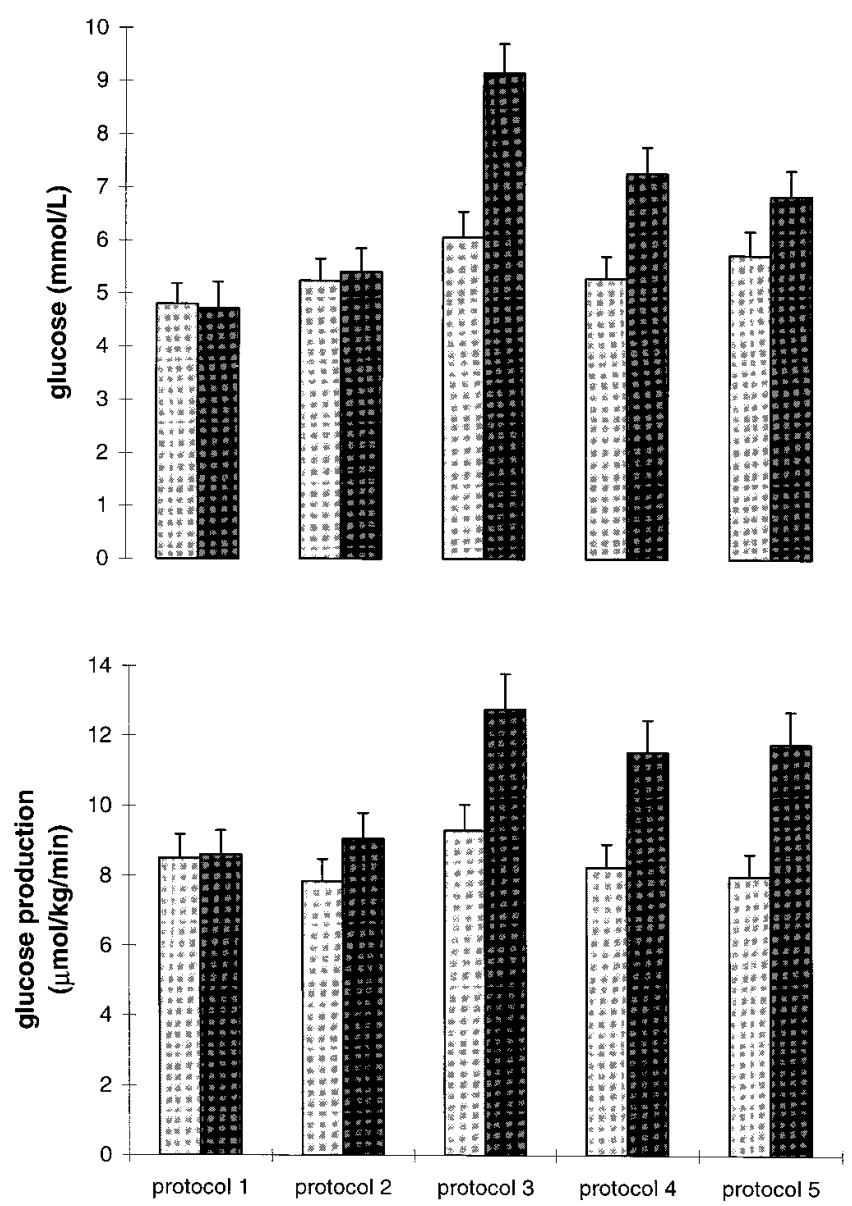

Figure 7. Values for endogenous glucose production were calculated from enrichments of $\left[6,6-{ }^{2} \mathrm{H}_{2}\right]$-glucose and are expressed as $\mu \mathrm{mol} / \mathrm{kg} /$ min. All endogenous glucose production values are expressed as mean values for the baseline (0-120 min; light gray bars) and plateau (300-360 min; dark gray bars) periods. The endogenous glucose production was significantly lower in protocols I and II, when glucagon levels were low, than in protocols III, IV, and V (when glucagon levels were high $)(P<0.02)$.

The changes from baseline of the mean plateau values $(\mu \mathrm{mol} / \mathrm{kg} / \mathrm{h}$ ) for nonoxidative leucine flux for protocols I, II, III, IV, and V were $37 \pm 4.5,41 \pm 4.3,14 \pm 3.5,28 \pm 3.1$, and $-14 \pm 3.3 \mu \mathrm{mol} / \mathrm{kg} / \mathrm{h}$, respectively. Percent changes from baseline at plateau for nonoxidative leucine flux values are shown in Fig. 6. Nonoxidative leucine flux was significantly increased above baseline in all protocols during which amino acids were infused (I-IV). The percent increase was less in protocol III (during selective hyperglucagonemia) than during the protocols in which glucagon was replaced at basal levels $(P<0.04)$ indicating an attenuation of amino acid-induced protein synthesis by glucagon. The difference between nonoxidative leucine flux in protocols II and III (mean $29 \mu \mathrm{mol} / \mathrm{kg} / \mathrm{h}$ ) was higher than the difference in endogenous leucine flux (19 $\mu \mathrm{mol} / \mathrm{kg} / \mathrm{h})$ between these two protocols $(P<0.05)$, indicating that protocol III was associated with less protein accretion than protocol II. The main difference between protocols III and IV is the addition of high levels of growth hormone and insulin, which seems to have partially reversed the negative effect of glucagon because there was a higher increment in nonoxidative leucine flux in protocol IV than in protocol III $(P<$
0.05). Although glucagon levels were similar in protocol III and $\mathrm{V}$, the infusion of amino acids resulted in a higher nonoxidative leucine flux, indicating that protein synthesis was stimulated by amino acids in spite of high glucagon levels.

Glucose (Fig. 7). Plasma concentration of glucose was not different at baseline and at plateau in protocols I and II. In all other protocols, glucose concentration was higher during plateau than during baseline $(P<0.01)$. The highest increase occurred in protocol III in which glucagon level was selectively increased.

The glucose production also followed the same pattern as glucose concentrations. In protocols I and II there was no increase in glucose production at plateau from the baseline. In all other protocols, including protocol $\mathrm{V}$, in which no amino acids were infused, glucose production increased above baseline $(P<0.01)$. The magnitude of increment in glucose production was greatest for protocol III, in which insulin was only replaced at basal levels.

\section{Discussion}

These studies have demonstrated that the circulating level of glucagon plays a critical role in determining plasma amino acid levels. This was seen to be true both in the postabsorptive state (protocol V) and during the infusion of amino acids (protocols I-IV). Glucagon's profound effect on amino acid disposal was clear from the experiments in which glucagon, insulin, and growth hormone were kept low (protocol II) resulting in the highest circulating concentrations of amino acids. This increase in amino acids was reversed by selectively increasing glucagon levels. The interaction of glucagon with other postprandial hormones, such as insulin and growth hormone, was more clearly defined in this study. Five separate experiments, performed in the same individuals under diverse study conditions, allowed us to clearly demonstrate changes in amino acid concentrations related to hormonal changes and to integrate these changes with dynamic measurements of protein turnover.

The differences in amino acid concentrations among our different protocols are mostly related to the changes in circulating glucagon levels. It is difficult to predict portal vein glucagon levels based on immunoreactive glucagon in peripheral circulation $(25,26)$. Based on a $30-40 \%$ first-pass extraction of glucagon (24-26) it is likely that the hepatic exposures to glucagon in protocols III, IV, and V are higher than in protocol I. However, these levels are within physiological range and clearly demonstrated glucagon's effect on amino acid disposal. The substantially lower amino acid concentrations seen in protocol III (high glucagon), in comparison with protocol II (low glucagon), could be attributed entirely to the higher glucagon levels. The glucagon-induced fall in amino acids was largely due to diminished concentrations of glucogenic amino acids. Endogenous leucine flux, an indicator of protein breakdown, was not different between protocols II and III, thereby excluding the possibility of changes in protein breakdown as the cause of differences in AA concentrations between the protocols. The associated increase in glucose production suggests that the glucogenic amino acids are consumed for gluconeogenesis. Glucagon's stimulation of gluconeogenesis is well established (27). As glucagon has little effect peripherally, glucagon-mediated hepatic uptake of amino acids is the most likely source of the lowered amino acid concentrations in the proto- 
cols in which glucagon levels were high. Glucagon has been shown to stimulate the hepatic uptake of glucogenic amino acids in in vitro experiments (28-30), a finding supported by human studies $(13,31)$. The plasma concentrations of BCAA, especially leucine, were also lower during infusion of amino acids in protocol III (high glucagon) than in protocol IV (low glucagon, insulin, and growth hormone). The decline in plasma leucine concentration in protocol $\mathrm{V}$, in which no amino acids were infused, could be attributed to accelerated leucine oxidation. In all four protocols in which amino acids were infused (protocols I-IV) there was a substantial increase in leucine oxidation. High levels of glucagon during the infusion of amino acids (protocol III) were not associated with any greater enhancement of leucine oxidation than was achieved by infusion of amino acids during basal levels of glucagon replacement. The only other pathways by which leucine can be disposed are by transamination and incorporation in to protein, but there is no evidence of increased protein synthesis in protocol III. Transamination of leucine is substantially accelerated in type I diabetic patients during insulin deprivation, when glucagon levels are high (32) but glucagon has been shown to activate the enzyme complex of branched-chain 2-oxo acid dehydrogenase (33). However, there is no direct evidence of glucagon's stimulation of transamination. Glucagon is a thermogenic hormone $(34,35)$ and it is conceivable that amino acids are also used as a fuel.

It is intriguing that in this study insulin and growth hormone had a less pronounced effect on amino acid concentrations during an amino acid load than did glucagon, although insulin is credited as the most important postprandial hormone. The main difference between protocols III and IV is in the plasma concentrations of insulin and growth hormone. Although the total amino acid levels in these protocols are the same, the glucogenic amino acids tend to increase and BCAA tend to decrease in protocol IV. These changes in amino acid concentrations are most likely related to insulin. Insulin has been shown to decrease the plasma concentrations of BCAA in a dose-dependent manner (23). Growth hormone acutely has little effect on circulating amino acid concentrations (36). The complex interaction of hormones and substrates on protein turnover was striking in this protocol. In this study we only assessed the effects of insulin and growth hormone in conjunction with high glucagon and their effects independent of high glucagon were not tested.

Amino acids per se seem to inhibit protein breakdown, since endogenous leucine flux was decreased in a similar fashion in all protocols where amino acids were infused, irrespective of the profound changes in hormones. Previous studies have demonstrated the inhibitory effect of amino acids on protein breakdown $(9,37,38)$. This amino acid-induced inhibition of protein breakdown occurs in skeletal muscle $(38,39)$ and in liver (40). Insulin has been shown to inhibit leucine flux when given to insulin-deprived type I diabetic $(32,41)$ and healthy humans $(37,42,43)$. Insulin was present in all protocols, although in varying concentrations, and it appears that in the presence of amino acids insulin did not exert a dose-related effect on leucine flux as has been reported in the postabsorptive subjects without any amino acid infusion $(42,43)$. Perhaps, the maximal effect on endogenous leucine flux was achieved by the combination of insulin and amino acids. Growth hormone has no known effect on leucine flux and glucagon in the pres- ence of insulin has no effect on leucine flux consistent with previous observations $(9,44,45)$.

Leucine oxidation also increased by $\geq 100 \%$ above baseline levels in all of the protocols in which amino acids were infused (protocols I-IV). Hyperglucagonemia has been shown to enhance leucine oxidation during insulin deprivation (9) and to a lesser degree during insulin replacement (44). This latter finding was confirmed by protocol $\mathrm{V}$ (high glucagon but basal insulin replacement) in which no amino acids were infused and explains the decline in plasma leucine levels. Changes in hormones did not modulate this profound enhancement of leucine oxidation during amino acid infusion. It is likely that the stimulation of leucine oxidation by amino acids and glucagon is by activation of the same enzyme complex and that, if the maximal effect is achieved by one stimulant, the second (possibly weaker) stimulant has no additional effect. The transamination product of leucine, alpha-KIC is a specific activator of branched-chain alpha-keto acid dehydrogenase, the enzyme responsible for oxidation of BCAA in skeletal muscle, heart, and adipocytes (46). Since glucagon activates this enzyme complex only in the liver (33), it is conceivable that amino acid effect was more pronounced than that of glucagon. However, it is intriguing that this effect of leucine was not evident in a human study in which leucine alone was infused (47) but occurred subsequently in this study when an amino acid mixture was infused.

The finding that hyperglucagonemia increases the rate of leucine oxidation in the fasted state, and thereby the rate of irreversible loss of an essential amino acid from the amino acid pool, adds further mechanistic support to glucagon's role as a protein catabolic hormone. These results are consistent with the findings of other investigators $(44,48)$ and our own (9). An animal study by Flakoll et al. (49) has found an only $12 \%$ increase in leucine oxidation by glucagon which did not reach any statistical significance. Methodological differences and species differences may explain the difference between this study and other human studies. Variations in the metabolic effects of glucagon between species are well documented (50). The real difference in results between Flakoll's data and our own may be more one of magnitude of effect rather than direction.

Whole body nonoxidative leucine flux, a putative marker of protein synthesis, was significantly increased above baseline levels whenever amino acids were infused (protocols I-IV). In protocol III, when amino acids were infused during isolated hyperglucagonemia, the increase in nonoxidative leucine flux above baseline was less pronounced than seen in protocol II, in which glucagon was infused only at basal levels. Hyperglucagonemia thus attenuates amino acid-induced stimulation of protein synthesis. This finding supports the report by Woodside et al. (51) in liver perfusion studies in which they demonstrated that glucagon inhibits protein synthesis and this effect was strongly potentiated when amino acid concentrations were increased in the perfusate. When insulin and growth hormone were added concomitantly with high levels of glucagon (protocol IV), this inhibitory effect of glucagon on protein synthesis was partially reversed. Stimulation of protein synthesis by growth hormone has been demonstrated previously in humans $(36,52)$. The combination of insulin and AA has also been shown to stimulate protein synthesis $(37,41,42,53)$. This enhanced protein synthesis could explain the reduced BCAA 
concentrations seen in protocol IV in comparison with protocol III, since no changes in leucine flux and oxidation occurred.

This study also provided a unique opportunity to measure whole body leucine kinetics in the same subjects on five separate occasions under identical study conditions. The narrow ranges for the three measured parameters of whole body leucine kinetics in the fasting state in this study were striking. Protein turnover was seen to occur at a relatively constant rate in humans on a day-to-day basis in these studies, suggesting that the remodeling process of tissue proteins is under tight physiological control. The coefficient of variation between five separate studies in the same subjects was $<4 \%$. This is comparable with the coefficient of variation seen in resting metabolic rate (54), $\sim 25 \%$ of which is determined by protein turnover.

Lack of stimulation of glucose production by amino acids (protocol I) is consistent with a previous report (55) which demonstrated substrate-induced stimulation of gluconeogenesis without any increase in glucose production. When high levels of glucagon were infused (protocols III, IV, and V), the rate of appearance of glucose was significantly increased above baseline levels $(P<0.02)$ compared with when levels of glucagon were lower (protocols I and II). The greatly increased rates of disposal of alanine and the other gluconeogenic amino acids during the protocols in which glucagon levels were high (protocols III, IV, and V) suggest that gluconeogenesis contributed a large proportion of the increased glucose production. The chief determinant of glucose production in these studies is the level of circulating glucagon, since the infusion of amino acids during low replacement levels of glucagon (protocol II) did not increase glucose production and glucose production increased during hyperglucagonemia without infusion of any amino acids (protocol V). It is likely that the small increment seen in insulin in protocol I inhibited glycogenolysis but did not inhibit the stimulation of gluconeogenesis by the amino acid load, as previously reported (55). The net effect is that the glucose production rate remained unchanged. Although both amino acids $(51,56)$ and glucagon $(27)$ are known to stimulate gluconeogenesis, substrate-induced gluconeogenesis does not increase glucose production (55).

The current studies provided a clear demonstration of the interaction between three hormones usually stimulated by protein meal or amino acid load in determining the postprandial amino acid profile in humans. The protein dynamic studies are found to be highly reproducible under the same study conditions and these studies provided a biochemical basis for hormonally mediated changes in circulating amino acids after an amino acid load. Amino acids not only inhibit protein breakdown, but promote leucine oxidation. These profound effects are not influenced by changes in the levels of hormones that occurred in this study. Glucagon is the main hormone determining the circulating amino acid concentration after an amino acid load. Glucagon's main effect on amino acids during an amino acid load is to increase the consumption of glucogenic amino acids, presumably for gluconeogenesis. It is likely that, by this diversion of amino acids, glucagon diminishes the precursor pool of amino acids available for protein synthesis, thus inhibiting the amino acid-induced stimulation of protein synthesis. Insulin and growth hormone only partially reversed the negative effect of glucagon on protein synthesis. These findings provide further evidence that glucagon is a catabolic hormone when present in physiologically high levels.

\section{Acknowledgments}

We are particularly grateful to our volunteers for their diligent and generous participation, the skilled technical support from Patricia Baumann, David Ebenstein, Janice Long, Gale Bess, Patricia Mead, and Dawn Morse, and Amy Wagner for her secretarial support. We gratefully acknowledge the helpful comments of our colleagues Drs. Rizza, Butler, and Rooyackers.

This work has been supported by Public Health Service grants RO1 DK 41973, GCRC RR109, and GCRC RR00585.

\section{References}

1. Rocha, D.M., F. Santeusanio, G.R. Faloona, and R.H. Unger. 1973. Abnormal pancreatic alpha cell function in bacterial infections. N. Engl. J. Med. 288:700-703.

2. Wilmore, D.W., J.A. Moylan, B.A. Pruitt, C.A. Lindsey, G.R. Faloona, and R.H. Unger. 1974. Hyperglucagonemia after burns. Lancet. 19:73-75.

3. Meguid, M.M., M.F. Brennan, T.T. Aoki, W.A. Muller, M.R. Ball, and F.D. Moore. 1974. Hormone-substrate interrelationships following trauma. Arch. Surg. 109:776-783.

4. McCullough, A.J., K.D. Mullen, A.S. Tavill, and S.C. Kalhan. 1992. In vivo differences between the turnover rates of leucine and leucine's ketoacid in stable cirrhosis. Gastroenterology. 103:571-578.

5. Russell, R.C.G., C.J. Walker, and S.R. Bloom. 1992. Hyperglucagonemia in the surgical patient. Br. Med. J. 1:10-12.

6. Mallison, C.N., S.R. Bloom, A.P. Warin, P.R. Salomon, and B. Cox. 1974. A glucagonoma syndrome. Lancet. 2:1-5.

7. Roth, E., F. Mulbacher, J. Karner, G. Hamilton, and J. Funovics. 1987. Free amino acid levels in muscle and liver of a patient with glucagonoma syndrome. Metab. Clin. Exp. 26:7-13.

8. Nair, K.S., D. Halliday, D.E. Matthews, and S.L. Welle. 1987. Hyperglucagonemia during insulin deficiency accelerates protein catabolism. Am. J. Physiol. 253:E208-E213.

9. Boden, G., R.W. Master, I. Rezvani, J.P. Palmer, T.E. Lobe, and O.E. Owen. 1980. Glucagon deficiency and hyperaminoacidemia after total pancreatectomy. J. Clin. Invest. 65:706-716.

10. Cahill, G.F. 1971. Physiology of insulin in man. Diabetes. 20:785-799.

11. Unger, R.H., E. Ohneda, E. Aquilar-Parada, and A.M. Eisentraut. 1986. The role of aminogenic glucagon secretion in blood glucose homeostasis. $J$. Clin. Invest. 77:1797-1804.

12. Assan, R.M., M. Marre, M. Gormley, and P.J. Lefebvre, editors. 1983. The amino acid induced secretion of glucagon. In Glucagon II. Springer-Verlag, Berlin. 19-41.

13. Boden, G., L. Tappy, F. Jadali, R.D. Hoeldtke, I. Rezvani, and O.E. Owen. 1990. Role of glucagon in disposal of an amino acid load. Am. J. Physiol. 259:E225-E232.

14. Abumrad, N.N., D. Rabin, M.P. Diamond, and W.W. Lacy. 1981. Use of a heated superficial hand vein as an alternative site for the measurement of amino acid concentrations and for the study of glucose and alanine kinetics in man. Metab. Clin. Exp. 30:936-940.

15. Copeland, K.C., F.A. Kenney, and K.S. Nair. 1992. Heated dorsal hand vein sampling for metabolic studies: a reappraisal. Am. J. Physiol. 263:E1010 E1014.

16. Matthews, D.E., D.M. Bier, M.J. Rennie, R.H.T. Edwards, D. Halliday, D.J. Millward, and G.A. Clugston. 1981. Regulation of leucine metabolism in man: a stable isotope study. Science (Wash. DC). 214:1129-1131.

17. Halliday, D., and W.W.C. Read. 1981. Mass spectrometric assay of stable isotopic enrichment for the estimation of protein turnover in man. Proc. Nutr. Soc. 40:321-334.

18. Nair, K.S., J.S. Garrow, C. Ford, R.F. Mahler, and D. Halliday. 1983. Effect of poor diabetic control and obesity on whole body protein metabolism in man. Diabetologia. 25:400-403.

19. Matthews, D.E., K.J. Motil, D.K. Rohrbaugh, J.F. Burke, V.R. Young, and D.M. Bier. 1980. Measurement of leucine metabolism in man from a primed, continuous infusion of L-[1-C-13]leucine. Am. J. Physiol. 238:E473E479.

20. Wolfe, R.R., R.D. Goodenough, M.H. Wolfe, G.T. Royle, and E.R. Nadel. 1982. Isotopic analysis of leucine and urea metabolism in exercising humans. J. Appl. Physiol. 52:458-466.

21. Schwenk, W.F., B. Beaufrere, and M.W. Haymond. 1985. Use of reciprocal pool specific activities to model leucine metabolism in humans. Am. J. Physiol. 249:E646-E650.

22. Bier, D.M., K.J. Arnold, W.R. Sherman, W.H. Holland, W.F. Holmes, and D.M. Kipnis. 1977. In-vivo measurement of glucose and alanine metabolism with stable isotopic tracers. Diabetes. 26:1005-1015.

23. Hill, D.W., F.H. Walter, T.D. Wilson, and J.D. Stuart. 1979. High performance liquid chromatographic determination of amino acids in the picomole 
range. Ann. Chem. 51:1338-1341.

24. Jaspan, J.B., J. Ruddick, and E. Rayfield. 1984. Transhepatic glucagon gradients in man: evidence for glucagon extraction by human liver. J. Clin. Endocrinol. \& Metab. 58:287-292.

25. Blackard, W.G., N.C. Nelson, and S.S. Andrews. 1974. Portal and peripheral vein immunoreactive glucagon concentrations after arginine or glucose infusions. Diabetes. 23:199-202.

26. Jaspan, J.B., K.S. Plonsky, M. Lewis, J. Pensler, W. Pugh, A.R. Moossa, and A.H. Rubenstein. 1981. Hepatic metabolism of glucagon in the dog: contribution of the liver to overall metabolic disposal of glucagon. Am. J. Physiol. 240:E233-E244.

27. Claus, T.H. C.R. Park, S.J. Pilkis, and P J. Lefebvre, editors. 1983. Glucagon and gluconeogenesis. In Glucagon I. Springer-Verlag, Berlin. 315-360

28. Fehlman, M., A. Le Cam, and P. Freychet. 1979. Insulin and glucagon stimulated transport in isolated rat hepatocytes. J. Biol. Chem. 254:10431-10437.

29. Kelley, D.S., J.D. Shull, and V.R. Potter. 1980. Hormonal regulation of amino acid transport and cAMP production in monolayer cultures of rat hepatocytes. J. Cell. Physiol. 103:159-168.

30. Mallette, L.E., J.H. Exton, and C.R. Park. 1969. Control of gluconeogenesis from amino acids in the perfused rat liver. J. Biol. Chem. 244:5713-5723.

31. Boden, G., I. Rezvani, and O.E. Owen. 1984. Effects of glucagon on plasma amino acids. J. Clin. Invest. 73:785-793.

32. Nair, K.S., G.C. Ford, K. Ekberg, E. Fernqvist-Forbes, and J. Wahren. 1995. Protein dynamics in whole body and in splanchnic and leg tissues in type I diabetic patients. J. Clin. Invest. 95:2926-2937.

33. Block, K.P., B.W. Heywood, M.G. Buse, and A.E. Harper. 1985. Activation of rat liver branched-chain 2-oxo acid dehydrogenase in vivo by glucagon and adrenaline. Biochem. J. 232:593-597.

34. Nair, K.S. 1987. Hyperglucagonemia increases resting metabolic rate in man during insulin deficiency. J. Clin. Endocrinol. \& Metab. 64:896-900.

35. Calles-Escandon, J. 1994. Insulin dissociates hepatic glucose cycling and glucagon-induced thermogenesis in man. Metab. Clin. Exp. 43:1000-1005.

36. Copeland, K.C., and K.S. Nair. 1994. Acute growth hormone effects on amino acid and lipid metabolism. J. Clin. Endocrinol. \& Metab. 78:1040-1047.

37. Castellino, P., L. Luzi, D.C. Simonson, M. Haymond, and R.A. DeFronzo. 1987. Effect of insulin and plasma amino acid concentrations on leucine metabolism in man. Role of substrate availability on estimates of whole body protein synthesis. J. Clin. Invest. 80:1784-1793.

38. Louard, R.J., E.J. Barrett, and R.A. Gelfand. 1990. Effect of infused branched-chain amino acids on muscle and whole-body amino acid metabolism in man. Clin. Sci. 79:457-466.

39. Nair, K.S., D.E. Matthews, S.L. Welle, and T. Braiman. 1992. Effect of leucine on amino acid and glucose metabolism in humans. Metab. Clin. Exp. 41: 643-648.

40. Mortimore, G.E., A.R. Poso, and B.R. Lardeux. 1989. Mechanism and regulation of protein degradation in liver. Diabetes Metab. Rev. 5:49-70.

41. Luzi, L., P. Castellino, D.C. Simonson, A.S. Petrides, and R.A. DeFronzo. 1990. Leucine metabolism in IDDM. Role of insulin and substrate availability. Diabetes. 39:38-48.

42. Tessari, P., S. Inchiostro, G. Biolo, R. Trevisan, G. Fantin, M.C. Marescotti, E. Iori, A. Tiengo, and G. Crepaldi. 1987. Differential effects of hyperinsulinemia and hyperaminoacidemia on leucine-carbon metabolism in vivo. $J$. Clin. Invest. 79:1062-1069.

43. Fukagawa, N.K., K.L. Minaker, J.W. Rowe, M.N. Goodman, D.E. Matthews, D.M. Bier, and V.R. Young. 1985. Insulin-mediated reduction of whole body protein breakdown. Dose-response effects on leucine metabolism in postabsorptive men. J. Clin. Invest. 76:2306-2311.

44. Hartl, W.H., H. Miyoshi, F. Jahoor, S. Klein, D. Elahi, and R.R. Wolfe. 1990. Bradykinin attenuates glucagon-induced leucine oxidation in humans. Am. J. Physiol. 259:E239-E245.

45. Couet, C., N.K. Fukagawa, D.E. Matthews, D.M. Bier, and V.R. Young. 1990. Plasma amino acid kinetics during acute states of glucagon deficiency and excess in healthy adults. Am. J. Physiol. 258:E78-E85.

46. May, M.E., and M.G. Buse. 1989. Effects of branched-chain amino acids on protein turnover. Diabetes Metab. Rev. 5:227-245.

47. Nair, K.S., R.G. Schwartz, and S. Welle. 1992. Leucine as a regulator of whole body and skeletal muscle protein metabolism in humans. Am. J. Physiol. 263:E928-E934.

48. Almdal, T.P., and H. Vilstrup. 1988. Exogenous hyperglucagonaemia in insulin controlled diabetic rats increases urea excretion and nitrogen loss from organs. Diabetologia. 31:836-841.

49. Flakoll, P.J., M.J. Borel, L.S. Wentzel, P.E. Williams, D.B. Lacy, and N.N. Abumrad. 1994. The role of glucagon in the control of protein and amino acid metabolism in vivo. Metab. Clin. Exp. 43:1509-1516.

50. Silva, S.V., and J.R. Mercer. 1992. The control of protein degradation in monolayer cultures of cat hepatocytes. Int. J. Biochem. 24:1651-1656.

51. Woodside, K.H., W.F. Ward, and G.E. Mortimore. 1974. Effects of glucagon on general protein degradation and synthesis in perfused rat liver. J. Biol. Chem. 249:5458-5463.

52. Fryburg, D.A., R.J. Louard, R.A. Gelfand, K.E. Gerow, and E.J. Barrett. 1991. Growth hormone (GH) stimulates protein synthesis (PS) and blunts insulin's (I) anti-proteolytic action on forearm (FA) skeletal muscle (SM) of normal man. Diabetes. XX:XXa. (Abstr.)

53. Flakoll, P.J., M. Kulaylat, M. Frexes-Steed, H. Hourani, L.L. Brown, J.O. Hill, and N.N. Abumrad. 1989. Amino acids augment insulin's suppression of whole body proteolysis. Am. J. Physiol. 257:E839-E847.

54. Welle, S., and K.S. Nair. 1990. Relationship of resting metabolic rate to body composition and protein turnover. Am. J. Physiol. 258:E990-E998.

55. Jenssen, T., N. Nurjhan, A. Consoli, and J.E. Gerich. 1990. Failure of substrate-induced gluconeogenesis to increase overall glucose appearance in normal humans. J. Clin. Invest. 86:489-497.

56. Brockman, R.P., and E.N. Bergman. 1975. Effect of glucagon on plasma alanine and glutamine metabolism and hepatic gluconeogenesis in man. Am. J. Physiol. 228:1627-1633. 